\title{
A Perspective: Active Role of Lipids in Neurotransmitter Dynamics
}

\author{
Pekka A. Postila ${ }^{1,2}$ (D) Tomasz Róg ${ }^{3}$ \\ Received: 6 June 2019 / Accepted: 1 September 2019/Published online: 8 October 2019 \\ (C) The Author(s) 2019
}

\begin{abstract}
Synaptic neurotransmission is generally considered as a function of membrane-embedded receptors and ion channels in response to the neurotransmitter (NT) release and binding. This perspective aims to widen the protein-centric view by including another vital component - the synaptic membrane - in the discussion. A vast set of atomistic molecular dynamics simulations and biophysical experiments indicate that NTs are divided into membrane-binding and membrane-nonbinding categories. The binary choice takes place at the water-membrane interface and follows closely the positioning of the receptors' binding sites in relation to the membrane. Accordingly, when a lipophilic NT is on route to a membrane-buried binding site, it adheres on the membrane and, then, travels along its plane towards the receptor. In contrast, lipophobic NTs, which are destined to bind into receptors with extracellular binding sites, prefer the water phase. This membrane-based sorting splits the neurotransmission into membraneindependent and membrane-dependent mechanisms and should make the NT binding into the receptors more efficient than random diffusion would allow. The potential implications and notable exceptions to the mechanisms are discussed here. Importantly, maintaining specific membrane lipid compositions (MLCs) at the synapses, especially regarding anionic lipids, affect the level of NT-membrane association. These effects provide a plausible link between the MLC imbalances and neurological diseases such as depression or Parkinson's disease. Moreover, the membrane plays a vital role in other phases of the NT life cycle, including storage and release from the synaptic vesicles, transport from the synaptic cleft, as well as their synthesis and degradation.
\end{abstract}

Keywords Synaptic neurotransmission $\cdot$ Neurotransmitter $\cdot$ Synaptic receptor $\cdot$ Membrane-based sorting $\cdot$ Molecular dynamics (MD) · Membrane lipid composition (MLC)

\section{Synaptic Membrane Plays a Role in Neurotransmission?}

From the traditional viewpoint, the synaptic membrane and its lipids are acknowledged to play a crucial and yet somewhat passive role in the synaptic neurotransmission.

The two adjacent neurons in the synapse can communicate with each other via chemical messengers or neurotransmitters (NTs) that burst out of the presynaptic membrane upon the arrival of the action potential, diffuse across the synaptic cleft

Tomasz Róg

tomasz.rog@gmail.com

1 Department of Biological and Environmental Science, University of Jyvaskyla, P.O. Box 35, FI-40014 Jyväskylä, Finland

2 Structural Bioinformatics Laboratory, Biochemistry, Faculty of Science and Engineering, Åbo Akademi University, FI-20500 Turku, Finland

3 Department of Physics, University of Helsinki, P.O. Box 64, FI-00014 Helsinki, Finland and eventually bind into the receptors embedded at the postsynaptic membrane $[1,2]$. Accordingly, the opposing membranes not only form barriers between the nerve cells but also house very specific membrane-embedded protein machineries such as receptors, voltage-gated ion channels, transporters, and intracellular proteins (so-called postsynaptic density) that modulate and relay the message across the cleft [3]. It is estimated that about 6600 unique proteins are present in the synapse [4], ensuring tight regulation of the signal transduction [5-7].

As a result, the role of lipids in the synaptic neurotransmission is predominately discussed in the context of their interactions and cooperation with these membrane proteins. Four prominent examples of active cooperation between lipids and proteins in the synapses are given below to demonstrate the wealth of data on the subject.

Firstly, lipids are known to be involved in the regulation of synapse development and plasticity. Tropomyosin receptor kinase B (TrkB) [8], which is a crucial protein in the synapse development, is regulated by cholesterol (CHOL) levels, i.e., losing its activity in membranes with low or high CHOL 
concentration [9]. Since CHOL levels increase in neurons during development reaching five times higher concentration in the adult brain compared with the early developmental stage [10], the highest level of TrkB activity is limited to a narrow time window of the brain development [11].

Secondly, lipids are heavily involved in presynaptic vesicle release [12-14] — at least 36 protein species are under lipid regulation in this process [12]. Phosphatidylinositols (PIPs), including $\mathrm{PI}(4,5) \mathrm{P} 2$, PI $(3,4,5) \mathrm{P} 3$, PI4P, and other charged lipid species, are responsible for the recruitment of numerous proteins at the presynaptic membrane $[12,13,15,16]$. The paramount changes in the bilayer curvature during the vesicle fusion/fission are achieved via CHOL translocations between the leaflets or changes in the size ratio of the headgroups to hydrocarbon chains (thus lipid shape) $[13,17]$. Various phospholipases actively modulate lipid shape by synthetizing phosphatidic acid (PA) and di-acyl-glycerol (DAG), because lipid species with small headgroups promote negative membrane curvature. Phospholipases also produce lysophosphatidylcholine that has only a single hydrocarbon tail thats promotes positive membrane curvature. The curved regions of the lipid bilayer are specifically recognized by sensory proteins that contain the banana-shaped BAR (Bin Amphiphysin Rvs) domains [18].

Thirdly, neurotransmitter receptors are also regulated by lipids, mostly by direct interactions [19-23], e.g., cholesterol has been shown to function as a direct allosteric regulator of $\mathrm{G}$ protein-coupled receptors (GPCRs) [24, 25]. Polyunsaturated fatty acids (PUFAs) are essential in brain functions [26], including the regulation of GPCR oligomerization [27].

Fourthly, lipids function as protein structural elements, and, for this reason, they are frequently found in the X-ray crystal structures of membrane proteins (see Enkavi et al. 2019 [28]). For example, CHOL is clearly visible in the 3D structures of serotonin [29], cannabinoid [30], $\mu$-opioid [31], K-opioid [32], muscarinic acetylcholine [33], and adenosine [34] receptors, as well as serotonin [35] and dopamine [36] transporters. These cocrystallized or conserved lipids are likely only the tip of the iceberg because the harsh conditions of the protein preparation during crystal preparation get rid of most lipids. Finally, lipidation or the process of covalently attaching lipid groups into membrane proteins, namely palmitoylation, and prenylation, affects numerous functions in the synapses [37, 38].

A growing number of studies indicate that direct and specific NT-lipid interactions could affect the signaling process in addition to the well-documented lipid-protein interactions discussed above. However, due to the sheer amount of evidence that backs up the protein-centric view, too little attention has traditionally been given to the fact that lipids and membrane surfaces also affect NT diffusion or dynamics. Therefore, this perspective aims to widen the protein-centric view of synaptic neurotransmission to include also direct NTlipid interactions. By examining the published studies on the topic and connecting the dots, it becomes evident that NTs are affected by the membrane environment at every stage of their lifecycles.

\section{Evidence of Direct Neurotransmitter-Lipid Interactions}

It is well established that hydrophobic ("water-hating") small molecules can bind on the cell membrane and, then, diffuse along its plane towards their membrane-embedded receptors (Fig. 1a) [39-41]. Accordingly, it comes to reason that the membrane has another integral and direct function in the synaptic neurotransmission that should not be overlooked; i.e., the NTs are either attracted (lipophilic) to or repelled (lipophobic) by the outer leaflet surface of the postsynaptic cell membrane [42]. However, water-soluble molecules with an amphipathic structure are also known to partition into a lipid bilayer, thus being lipophilic. Amphipathic molecules typically locate to the membrane-water interface (e.g., [43-47]) while hydrophobic molecules locate deeper into the hydrocarbon core of the membrane.

The membrane affinity or lipophilicity of small molecules such as drugs is reflected in their high octanol/water partition coefficients or $\log P$ values. Non-peptidic or conventional NTs are no exception to this fundamental rule, and their typical $\log P$ values (Fig. 2) follow the suggested membranewater phase sorting paradigm (Fig. 1b) [42]. It is, however, an understatement to say that octanol, which is used in the log $P$ assay, is too simple a model system for estimating the nuances of NT-membrane adherence that takes place with a complex cell membrane housing diverse sets of lipid species (Fig. 1) [48]. This is underscored by the fact that there exist 21,000 lipid species (The Lipid Maps Structure Database, http://lipidmaps.org/data/structure/), which can be arranged into a myriad of combinations. Thus, not surprisingly, the partitioning of drugs into biological membranes is much higher than predicted by $\log P$ values [49].

Endocannabinoids such as anandamide, which are derived directly from fatty acids and act as retrograde transmitters [50], deep membrane penetration, and lipid-like dynamics, are to be expected, but the level of membrane permeation or adherence is less evident for the conventional NTs. In fact, several computational and experimental studies have provided solid evidence on the effects of specific NT-lipid interactions and, moreover, highlighted the potential importance of membrane lipid composition (MLC) imbalances for neurological diseases [42, 48, 51-67].

In this respect, the lipophilic dopamine (Fig. 2) is possibly the most studied small molecule NT. Dopamine was confirmed to partition preferentially onto the membrane based on both atomistic molecular dynamics (MD) simulations (Fig. 3a,b) and experimental monolayer studies (Fig. 3c) [60]. The subsequent simulations with an alternative 
Fig. 1 The effect of

the membrane on small molecule diffusion and receptor entry. a

The ligands can either diffuse in

3D towards their membrane-

bound receptors (black dot; left)

or the 3D diffusion can transform into 2D diffusion along the membrane plane (curved line) prior to the receptor binding (right).

Reproduced with the permission from ref. [40]. Copyright 2009

Elsevier. b The membrane (brown opaque surface) adherence (lipophilicity) or repulsion (lipophobicity) of neurotransmitters (CPK models) is demonstrated for the norepinephrine (right) and glutamate (left), respectively, using atomistic molecular dynamics simulations. Reproduced with modifications from ref. [42] Copyright 2016 Postila et al. (https://creativecommons.org/ licenses/by/4.0/legalcode)
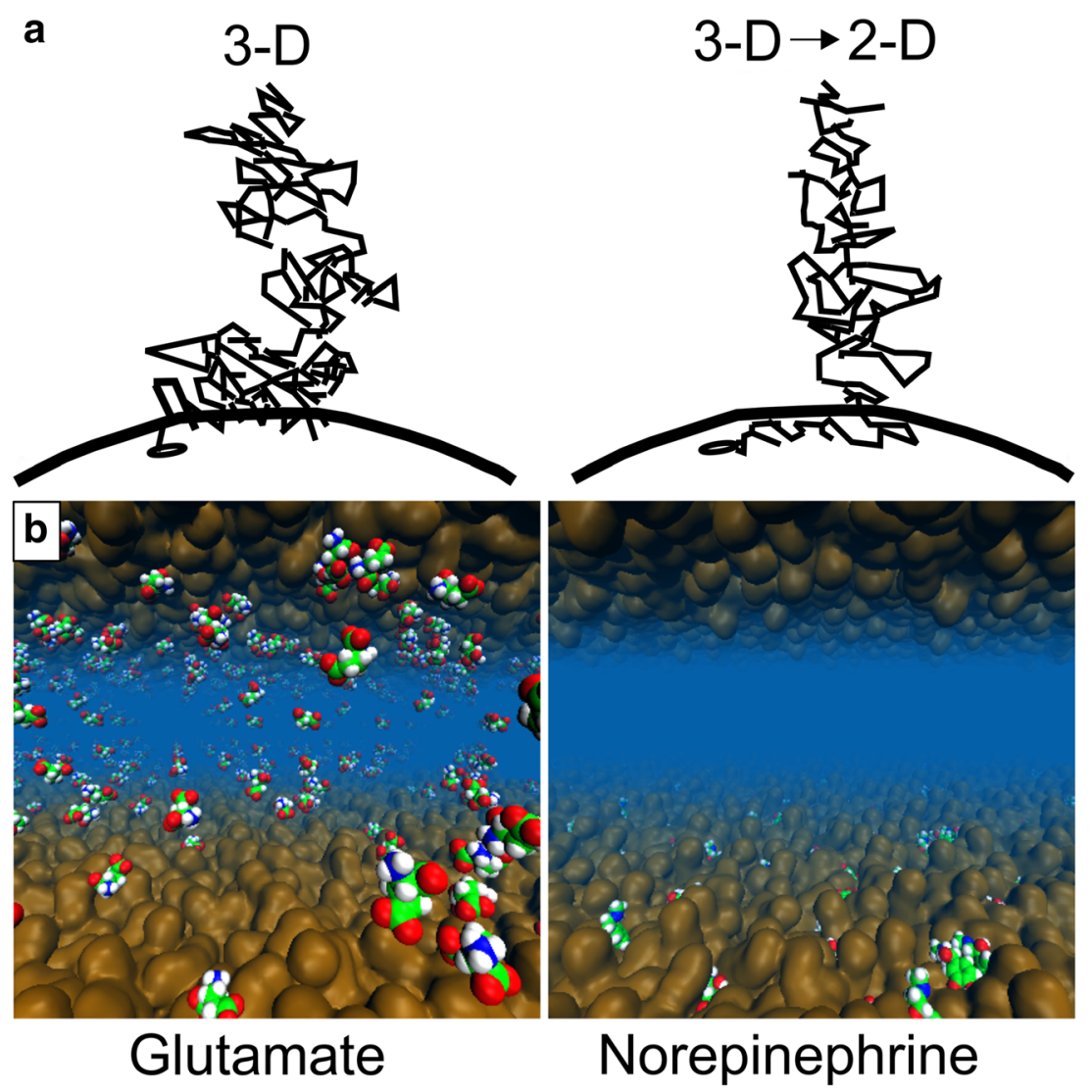

molecular mechanics force field methodology (OPLS vs. CHARMM) provided similar observations [42, 53]. These theoretical studies indicating strong dopamine-membrane association were further validated by calorimetric [62], nuclear magnetic resonance spectroscopy [63], and fluorescence microscopy [64] experiments.

Similarly, melatonin has been shown to partition onto lipid bilayers via MD simulations, neutron scattering and diffraction, infra-red spectroscopy, fluorescence spectroscopy, calorimetry, and Langmuir-Blodgett monolayer study [51-53, 65-67]. Serotonin was shown to interact with lipids in both theoretical and experimental studies [54, 68]. Adenosine, epinephrine (or adrenaline), and norepinephrine were shown to interact with lipids using MD simulations [42]. Trace amine: tyramine, octopamine, and tryptamine, having similar chemical structures to the above-discussed NTs, were also shown to have an affinity towards different membranes [55]. Finally, short peptidic NTs methionine-enkephalin and leucineenkephalin were shown to adhere to the membrane surface [61].

Following their low $\log P$ values (Fig. 2), polar or charged NTs such as $\gamma$-aminobutyrate (GABA), glycine, acetylcholine (Fig. 3), and glutamate are not observed to aggregate preferentially at the water-membrane interface in the MD simulations [42]. Despite this, sensitive experimental techniques show that even these lipophobic NTs form both attractive and repulsive interactions with the lipids [56]. Importantly, the membrane partitioning of NTs is modified by the presence of charged lipids or divalent cations [56].

In particular, GABA and glutamate were shown to interact with the lipid bilayers in the presence of $\mathrm{Ca}^{2+}$, while acetylcholine in these conditions was repulsed [59]. Next, acetylcholine was shown to be attracted towards bilayers containing negatively charged lipids $[42,56,59]$ and repulsed by a bilayer composed of zwitterionic lipids [56]. Similarly, zwitterionic NTs GABA and glycine were attracted towards bilayers containing anionic lipids and were hardly affected by neutral bilayers [56]. Finally, anionic glutamate was repulsed from negatively charged lipids and weakly attracted by a neutral bilayer [56]. It is noteworthy that these interactions lead to increased concentration of polar NTs at the membrane hydration layer [56] without penetration into the membrane core as is observed with the amphipathic NTs [42].

A distinct subset of small non-peptidic NTs are gaseous molecules such as nitric oxide (NO), carbon monoxide (CO), and hydrogen sulfide $\left(\mathrm{H}_{2} \mathrm{~S}\right)[69,70]$. The solubility of these gasses in organic solvents is higher than that of water; thus, their concentration in the lipid phase is relatively high. For example, the concentration of $\mathrm{NO}$ in the lipid bilayers is 4.4-fold higher than in water [71], and the concentration difference is 2.2-fold for $\mathrm{H}_{2} \mathrm{~S}$ [72]. Free energy calculations based on biased MD simulations are in agreement with these 


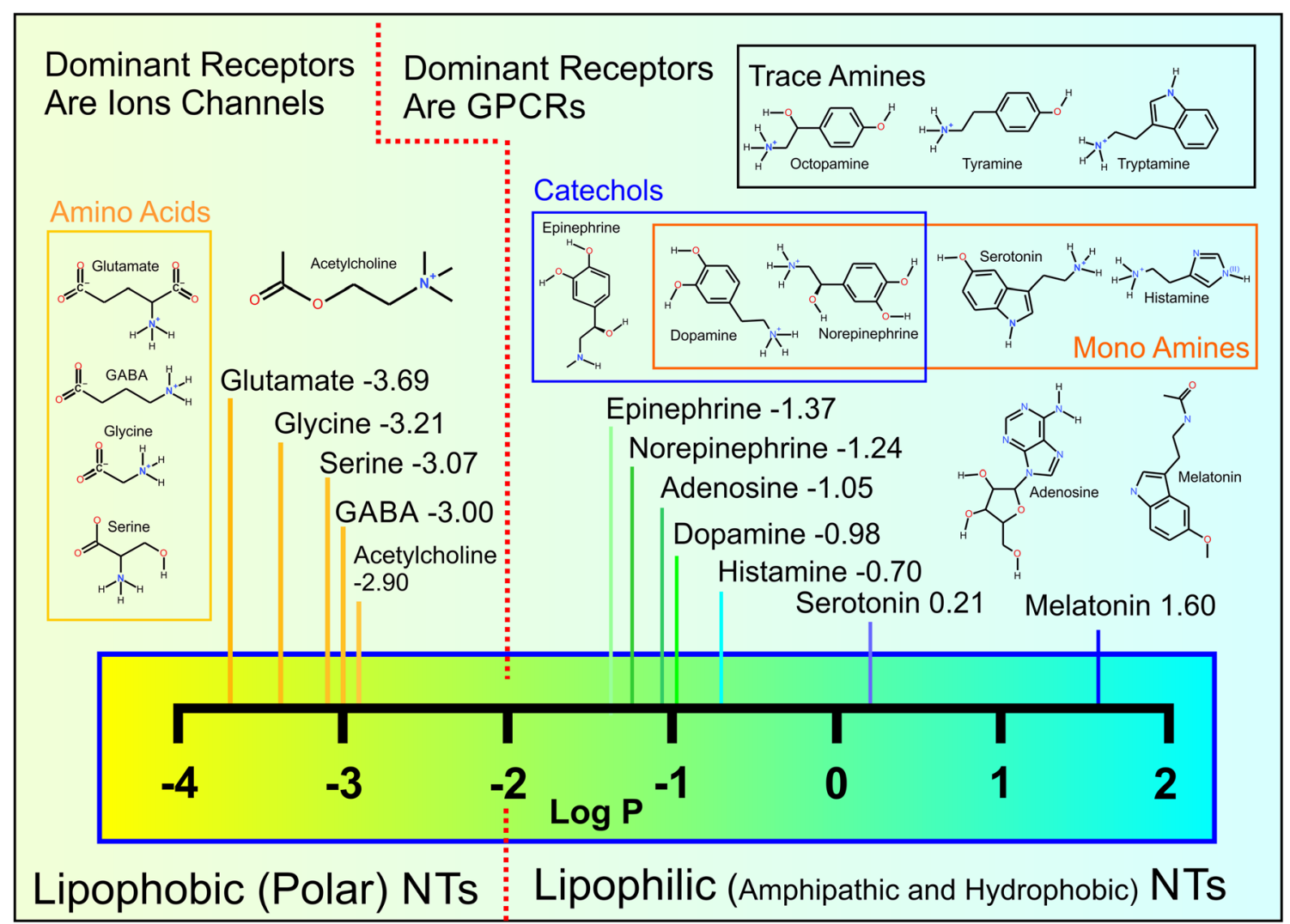

Fig. 2 Chemical structures and $\log P$ values of non-peptidic neurotransmitters. The given $\log P$ values are experimental except for acetylcholine (https://pubchem.ncbi.nlm.nih.gov/). The $\log P$ values suggest that the neurotransmitters (NTs) belong to either lipophobic $(-3.69$ to -2.90$)$ or lipophilic (-1.37 to 1.60$)$ categories. In reality, most of the NTs are

experimental results for both $\mathrm{NO}$ [73] and $\mathrm{H}_{2} \mathrm{~S}$ [74]. The partitioning of $\mathrm{CO}$ into lipid bilayers has been studied using MD simulations, which indicated similar behavior for $\mathrm{NO}$ and $\mathrm{O}_{2}$ [75]. This is not surprising considering that charge separation in $\mathrm{CO}$ is $0.021 \mathrm{e}$ and in NO 0.028e. It is also worth mentioning that xenon $(\mathrm{Xe})$, which is a gas with anesthetic properties, is highly soluble in lipid bilayers and most likely acquires its analgesic effects by targeting membrane proteins $[41,76]$.

\section{Synaptic Receptor Types vs. Lipid-Neurotransmitter Association}

The non-peptidic signal molecules can be divided roughly into two distinct categories based on the experiments: membranebinding (lipophilic) and membrane-nonbinding (lipophobic) NTs (Fig. 1) [42]. Those NTs such as dopamine with aromatic ring systems, apolar, or otherwise lipophilic/hydrophobic profiles adhere onto the membrane surface (see dopamine in Fig. 3 and norepinephrine in Fig. 1b). Not surprisingly, small lipophobic/hydrophilic NTs such as glutamate (Fig. 1b) or amphipathic molecules with both hydrophilic ("water-loving") or hydrophobic ("water-hating") groups whose combined effect determines how likely they are to remain in the water phase or to aggregate on the membrane, respectively.

acetylcholine with polar or charged moieties prefer to stay in the water phase instead of adhering onto the membrane (see acetylcholine in Fig. 3). This division of NTs into lipophilic and lipophobic groups is produced effectively by MD simulations with various lipid bilayer models [42], but it can be crudely deduced by simply relying on standard $\log P$ values as well [42] (Fig. 2).

The selective adhesion of NTs at the water-membrane interface is important due to the placement of their receptors' ligand-binding sites in respect to the synaptic membrane (Fig. 3) [42]. Lipophilic NTs bind preferentially onto the membrane surface from where they can diffuse along the membrane plane towards their membrane-buried binding sites of GPCRs (Figs. 4 and 5). Consequently, the 3D diffusion is transformed into planar 2D diffusion, facilitating presumably faster and more coordinated NT-receptor binding [40]. The most hydrophilic NTs remain preferentially in the water phase without notable membrane surface aggregation [42] - an arrangement that should make the entry into their receptors' extracellular ligand-binding sites faster and energetically more favorable than if the molecules would adhere on the membrane (Figs. 4 and 5). In effect, the membrane sorting places 


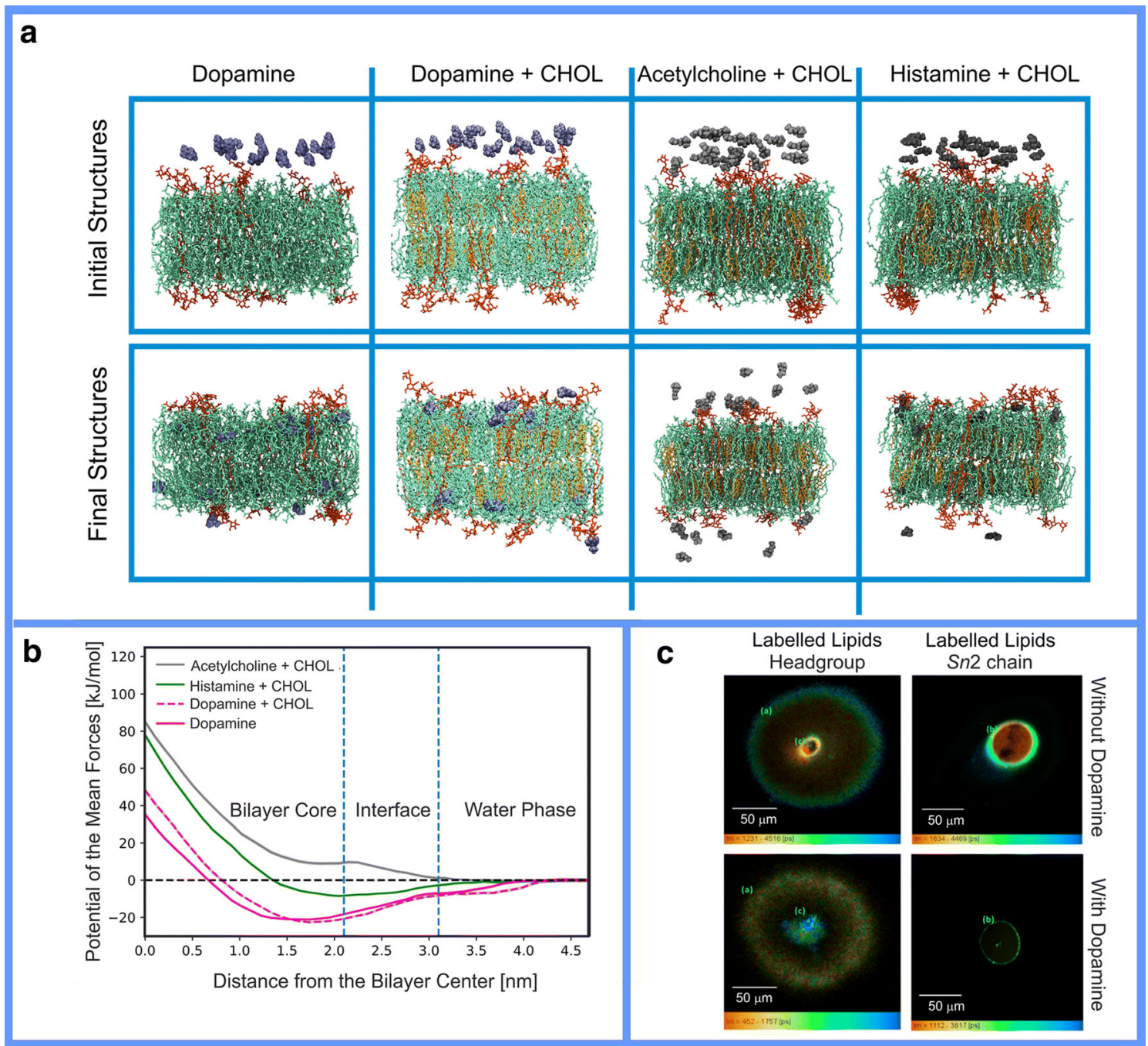

Fig. 3 a Snapshots of the initial (0 ns) and final configurations (500 ns) obtained in molecular dynamics (MD) simulations of lipid bilayers (stick models) composed of POPC (1-palmitoyl-2-oleoyl-sn-glycero-3phosphocholin; green), CHOL (cholesterol; orange), ganglioside GM1 (monosialotetrahexosylganglioside; red), in the presence of dopamine, acetylcholine, and histamine (blue or gray CPK models). Water is omitted for clarity. Reproduced with the permission from ref. [57]. Copyright 2018 Elsevier. b Free energy profiles of the neurotransmitters translocating thorough the lipid bilayer indicate that dopamine preferred a location at the core of the bilayer below the lipid headgroup region. The

the released lipophilic and lipophobic NTs closer to their receptors' binding sites than would otherwise be expected from a completely random 3D diffusion [40].

Based on the lipophilic/lipophobic membrane sorting and established locations of receptors' ligand-binding sites, the neurotransmission may be divided into (1) membraneindependent and (2) membrane-dependent mechanisms (Fig. 5) [42]. Accordingly, the polar/charged amino acids such as glutamate, glycine, and serine, or the amino acid-like GABA and acetylcholine would not adhere onto the synaptic membrane as they are destined to enter receptors with extracellular ligand-binding sites. Reciprocally, most hydrophobic NTs center of mass of the bilayer is at $0 \mathrm{~nm}$. Vertical blue dashed lines show approximate regions of the bilayer hydrocarbon core, the membrane-water interface, and water. Reproduced with the permission from ref. [57]. Copyright 2018 Elsevier. c Fluorescence lifetime imaging microscopy images of giant lipid vesicles containing nitrobenzoxadiazole (NBD)-labeled lipids at the headgroup or last carbon of the $\mathrm{Sn} 2$ chain in the absence and presence of dopamine. The images show dopamine aggregation at the membrane interior. Reproduced with the permission from ref. [64]. Copyright 2017 the American Chemical Association

such as dopamine, its precursor L-dopa, norepinephrine, epinephrine, adenosine, melatonin, and serotonin partition on the membrane, where the GPCRs have membrane-buried ligandbinding sites (Fig. 4).

Various simulation studies $[42,54,60,61]$ and biophysical experiments [51-54, 62-67] corroborate this mechanistic division; however, there are notable exceptions to the rule when focusing on the available receptor protein structures and possible MLCs.

Firstly, serotonin receptors have both extracellular and membrane-buried ligand-binding sites (Fig. 4), although the NT has a notably high $\log P$ value (Fig. 2) and prefers the 


\begin{tabular}{|c|c|c|c|c|}
\hline Receptor name & Receptor subtypes & Neurotransmitter & Mechanism of action & Ligand-binding site position \\
\hline Adenosine receptor & $A_{1}, A_{2 A-B}, A_{3}$ & adenosine & GPCR & membrane-buried \\
\hline Adrenergic receptor & ADR- $\alpha_{1 A, B, O}, \alpha_{2 A-C C}, \beta_{1-3}$ & (nor)epinephrine & GPCR & membrane-buried \\
\hline Dopamine receptor & $D_{1-5}$ & dopamine & GPCR & membrane-buried \\
\hline Histamine receptor & $\mathrm{H} 1-4$ & histamine & GPCR & membrane-buried \\
\hline Melatonin receptor & MT1-3 & melatonin & GPCR & membrane-buried \\
\hline Metabotropic serotonin receptor & $\begin{array}{c}5-\mathrm{HT}_{1 \mathrm{~A}-8,}, 5-\mathrm{HT}_{10-p} 5-\mathrm{HT}_{2 \mathrm{~A}-\mathrm{C}} 5- \\
\mathrm{HT}_{4}, 5-\mathrm{HT}_{5 \mathrm{~A}-\mathrm{B}}, 5-\mathrm{HT}_{6-7}\end{array}$ & serotonin & GPCR & membrane-buried \\
\hline Muscarinic acetylcholine receptor & mAch-M1-5 & acetylcholine & GPCR & membrane-buried \\
\hline $\mathrm{GABA}_{\mathrm{A}}$ receptor & $\begin{array}{c}\mathrm{GABA}_{\mathrm{A}}-\alpha 1-6 / \beta 1-3 / \gamma 1- \\
3 / \delta / \varepsilon / \pi / \theta, \rho 1-3\end{array}$ & GABA & ion channel & extracellular \\
\hline $\mathrm{GABA}_{8}$ receptor & $\mathrm{GABA}_{81-2}$ & GABA & GPCR & extracellular \\
\hline Glycine receptor & GlyR- $\alpha 1-4 / \beta$ & glycine & ion channel & extracellular \\
\hline lonotropic glutamate receptor & $\begin{array}{l}\text { GluA1-4, GluK1-5, GluN1, } \\
\text { GluN2A-D, GluN3A-B }\end{array}$ & $\begin{array}{c}\text { glysine, serine, glutamate, } \\
\text { aspartate }\end{array}$ & ion channel & extracellular \\
\hline lonotropic serotonin receptor & 5-HT3 & serotonin & ion channel & extracellular \\
\hline Metabotropic glutamate receptor & mGluR1-8 & glutamate & GPCR & extracellular \\
\hline Nicotinic acetylcholine receptor & nAch- $\alpha 1-10 / \beta 1-4, D, E, G$ & acetylcholine & ion channel & extracellular \\
\hline 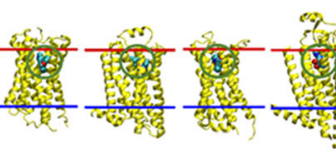 & 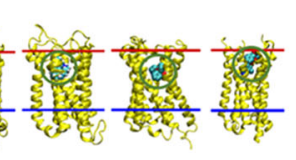 & 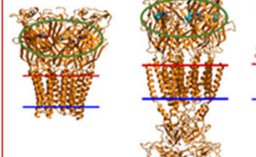 & 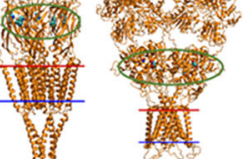 & $\frac{25}{435}$ \\
\hline$A D R \beta 2$ & MT2 mAch-M25-HT1B & GlyR-1 $\alpha / \beta$ GlyR-1 $\alpha / \beta$ & nAch- $\alpha$ & GluA2 \\
\hline
\end{tabular}

Fig. 4 The positions of ligand-binding sites of conventional synaptic receptors in the postsynaptic membrane. The approximate positions of the ligand-binding sites of $\mathrm{G}$ protein-coupled receptors (GPCRs) (yellow) and ion channel-forming receptors (orange) are circled green in the protein 3D structures (cartoon models). The inner and outer bilayer leaflets are shown with blue and red lines, respectively. Reproduced with modification from ref. [42]. Copyright 2016 Postila et al. (https:// creativecommons.org/licenses/by/4.0/legalcode) membrane surface to the water phase in both simulations and experiments $[42,79]$. The membrane preference of serotonin could be overcome by only increasing its secreted levels in those synapses where membrane adherence is unfavorably affecting the receptor entry. Secondly, although acetylcholine binds into the extracellular ligand-binding sites of both nicotinic acetylcholine receptor (Fig. 4) and acetylcholinesterase, the positively charged NT also has to enter the membrane- buried binding site of muscarinic acetylcholine receptor [80] (Fig. 4). The lack of membrane adherence seems unlikely to be overcome by only increasing the acetylcholine levels; however, acetylcholine could be forced to bind onto a membrane containing anionic lipids. In other words, the inconsistency of acetylcholine binding sites could, in theory, be explained by MLC differences between those synapses housing either nicotinic or muscarinic acetylcholine receptors (Fig. 4). By

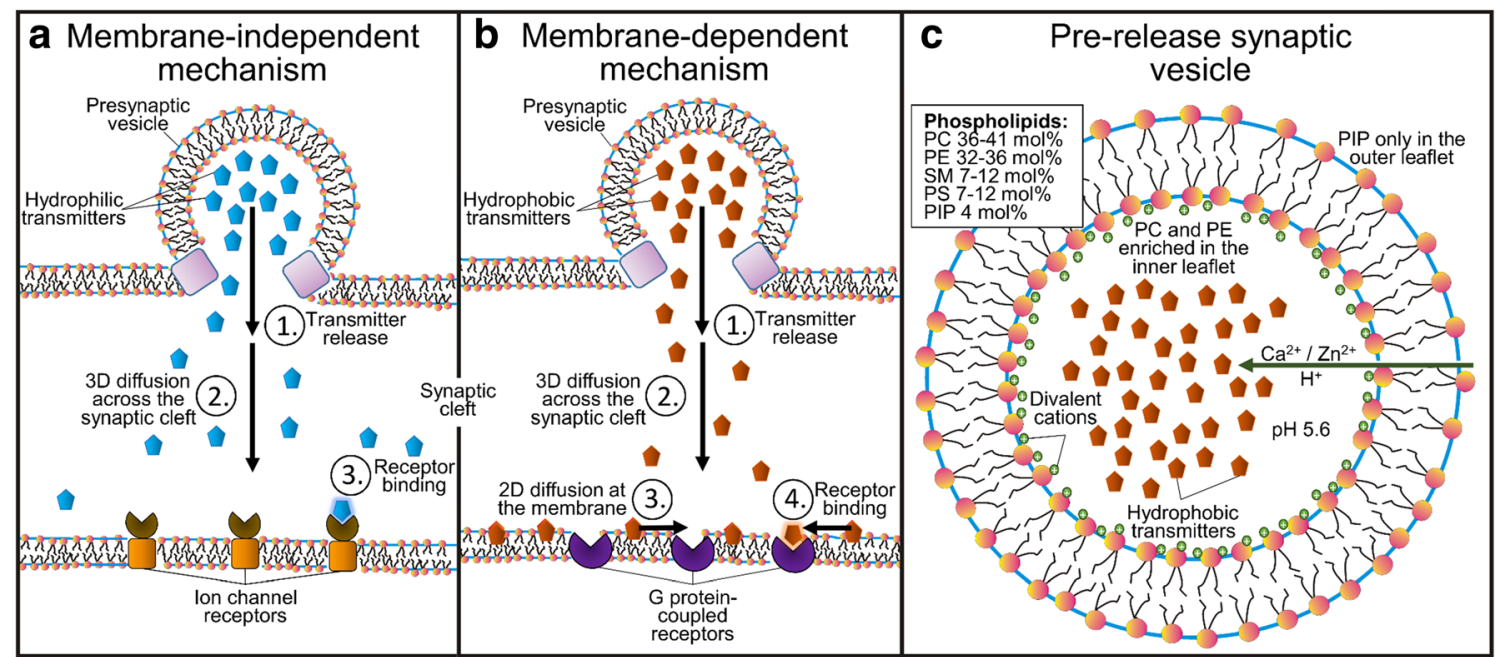

Fig. 5 Synaptic neurotransmission models. Left panel-membranedependent model: (1) release of lipophilic neurotransmitters (NTs), (2) diffusion across the synaptic cleft, (3) binding onto the postsynaptic membrane surface and 2D diffusion on the membrane plane, and, finally, binding into the receptors. Middle panel-membrane-independent model: (1) release of lipophobic NTs, (2) diffusion across the synaptic cleft, and binding into the receptors. Right panel - the presynaptic vesicle with its known lipid composition [77, 78]. Reproduced with the permission from ref. [58]. Copyright 2017 American Chemical Society 
regulating the MLC tightly, the NT entry would follow either the membrane-independent or membrane-dependent mechanism [42] (Fig. 4).

\section{The Effect of Membrane Lipid Composition on Neurotransmitter Dynamics}

The adjacent neurons form a synapse specialize in the release of specific NTs; for example, the neuromuscular junctions are packed with nicotinic acetylcholine receptors (Fig. 4) that selectively bind acetylcholine [81]. This means that the protein machinery both at the pre- and postsynaptic membranes is tightly regulated to match the needs of the secreted NT types in each synapse. Likewise, it comes to reason that also the MLCs would be specific for these different synapses and optimized to assure fast and efficient signaling with the NTs in question.

Recent lipidomics studies have led to the vast and rapid expansion of the available data on various organs, tissues, cell types, and cell organelles [82, 83]. Similarly, data concerning lipidome changes in pathological states, including neurological and mental disorders, provide new insight into the possible role of lipids in neuronal tissues [84-89]. Although no direct link has been established so far, it is easy to fathom how an imbalance in the strength of NT-membrane partitioning could contribute to, for example, major depressive disorder or Parkinson's disease. Typically, both conditions are treated by increasing the concentration of the responsible NTs in the neurons. With depression, antidepressants increase either the level of serotonin or dopamine at the synapse by blocking their transport or by inhibiting their catabolism. With Parkinson's disease, the dopamine precursor L-dopa, which, unlike dopamine diffuses across the blood-brain barrier, is administered to increase the effective dopamine levels. In theory, the local concentration of the NTs either at the membrane surface or in the water phase could be negatively affected by too strong or weak membrane association; thus, the MLC would be at least a partial culprit for the shortage of NTs that can bind into the receptors.

Despite the rapid progress of lipidomics analysis [90-93], the MLCs for specific synapses or neurons are not particularly well characterized to date. The synaptic membrane leaflets are expected to remind a typical animal cell: the extracellular leaflet being neutral and composed mainly of sphingolipids (SPH; Fig. 6), saturated phosphatidylcholine (PC; Fig. 6), and CHOL (Fig. 6); and its more anionic counterpart the intracellular leaflet containing more negatively charged lipids such as phosphatidylserine (PS; Fig. 6), PIP (Fig. 6), and phosphatidylglycerol (PG; Fig. 6) [94]. The only notable charged lipid species of the extracellular leaflet, whose levels are moderately high in the neurons where their molar fraction is in the order of few mol\%, are the glycolipids including gangliosides and sulfogalactosyl ceramides [95]. As their concentration can reach even $30 \mathrm{~mol} \%$ [96,97], glycolipids such as monosialotetrahexosylganglioside (GM1; Fig. 6) are potentially a vital membrane component affecting the NT dynamics via charge-related effects. Moreover, an aberration in sulfogalactosyl ceramide content in neurons was observed for the case of few neurodegenerative disorders $[98,99]$.

In fact, studies have shown that the main lipid classes in the synaptosome - a structure containing both the pre- and postsynaptic membranes, synaptic vesicles, and possibly fragments of other cells - follow this general pattern of animal cell MLC. Nevertheless, notable differences between the synaptosome and whole brain lipids have been observed [100]. A more accurate lipidomics study of the synaptosome, in which $\sim 80$ lipid species were identified, showed significant differences in the MLC of the synaptosome in comparison with the synaptic vesicle [101] (Fig. 4). Another recent lipidomics study of the postsynaptic membrane showed large changes in the lipid profile during brain development. It was shown that the amount of CHOL, SPH, and ether lipids increases with time. Moreover, the decrease of the number in short tails and an increase in the number of tails with six double bonds were observed [102]. In the central nervous system, CHOL originates from in situ performed synthesis [10], which takes place predominately in astrocytes [103]. Thus, the decrease of CHOL synthesis by astrocytes could lead to the impairment of the brain development and decrease of neuron growth in coculture of neurons with astrocytes [104].

The atomistic MD simulations [42, 54, 60, 61] (Fig. 3a, b) and experiments [51-56, 62-68] alike show that the lipid assortment indeed affects NT dynamics profoundly. Majority of the non-peptidic NTs are attracted towards the anionic membrane models to a varying degree $[42,56,59,62]$. That includes even the most charged and hydrophilic NTs such as GABA or glycine as they show a moderate level of adherence on the membrane models containing anionic lipid PS (Fig. 6), PG (Fig. 6), and phosphatidic acid [56]. This adherence onto the anionic membranes in comparison with the neutral membrane models is explained by the prevalent charge factor and electrostatic interactions: the anionic lipids attract the positively charged, amphipathic or zwitterionic NTs even if this charge-based attraction does not necessarily assure complete membrane preference over the water phase or full lipophilicity [56]. The only exception seems to be the anionic glutamate, which is repulsed by the anionic lipids [56].

With dopamine and histamine, the presence of physiologically relevant glycolipid GM1 (Fig. 6) lipid species was enough to enhance their already notably strong membrane preference based on the MD simulations [57]. The same effect could not be replicated with the acetylcholine, whose binding to muscarinic receptors (Fig. 4) should benefit from the membrane partitioning as suggested by the dualistic neurotransmission model (Fig. 5) [42]. The membrane adherence of 


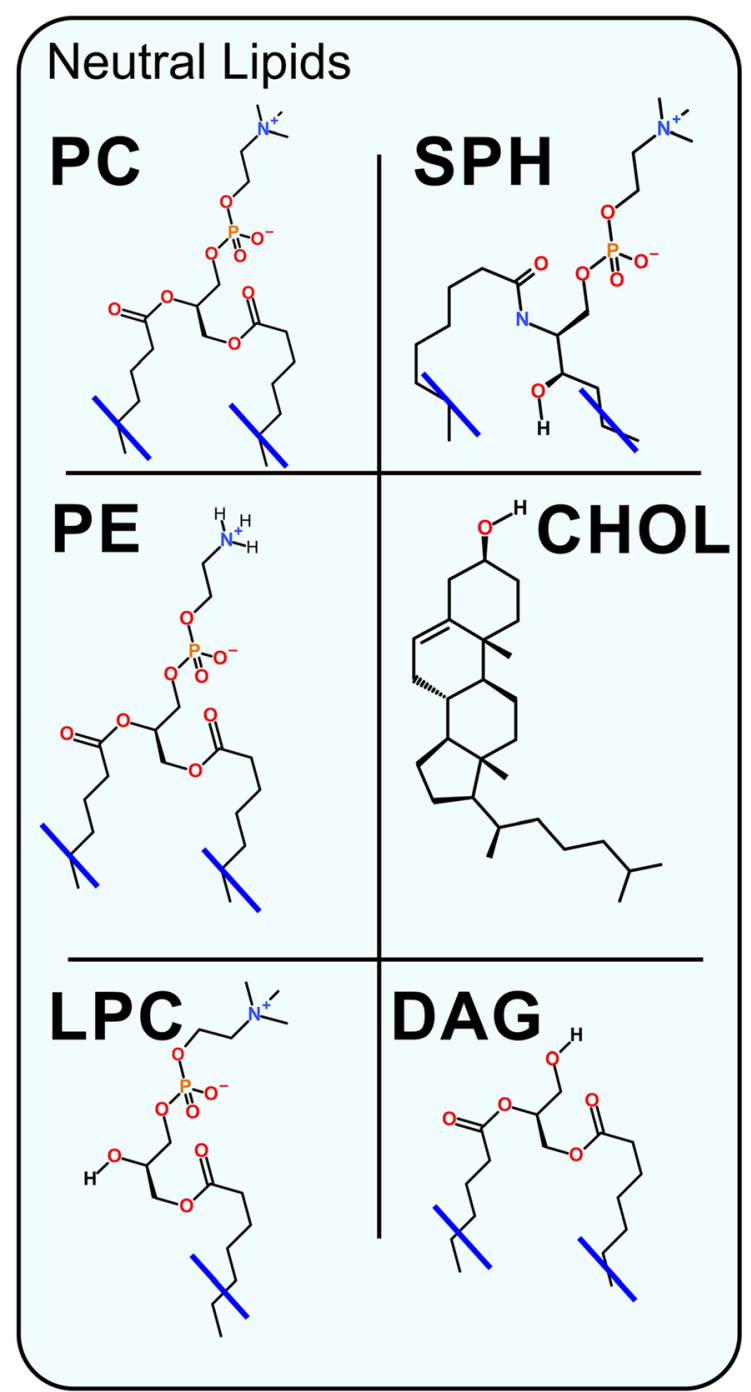

Fig. 6 Chemical structures of the most common lipids. PC, phosphatidylcholine; PE, phosphatidylethanolamine; SPH, sphingomyelin; CHOL, cholesterol; LPC, lysoPC; DAG, diacylglycerol;

acetylcholine is achieved with a membrane model containing PS in the simulations [42] and PS or PG experimentally [56]; however, these lipid types are more endogenous to the intracellular leaflet of the cell membrane than the typical extracellular leaflet. Thus, if stable membrane adherence of acetylcholine is indeed a prerequisite for the entry into the membraneburied ligand-binding site, the membrane housing the muscarinic receptors should contain lipids that are more anionic than the GM1 (Fig. 6).

It is well established that CHOL (Fig. 6) decreases the transport of gasses through lipid bilayers [41, 105-107]. NO diffusion in the lipid bilayers can be slowed down by $20-40 \%$ depending on the MLC $[108,109]$ and also the permeability coefficients of NO can be reduced by $17 \%$ [110]. MD simulations and free energy calculations indicate that $\mathrm{CO}$ and $\mathrm{NO}$ behave similarly in the CHOL-rich membrane environment [111]. Nevertheless, the diffusion of NO through biological

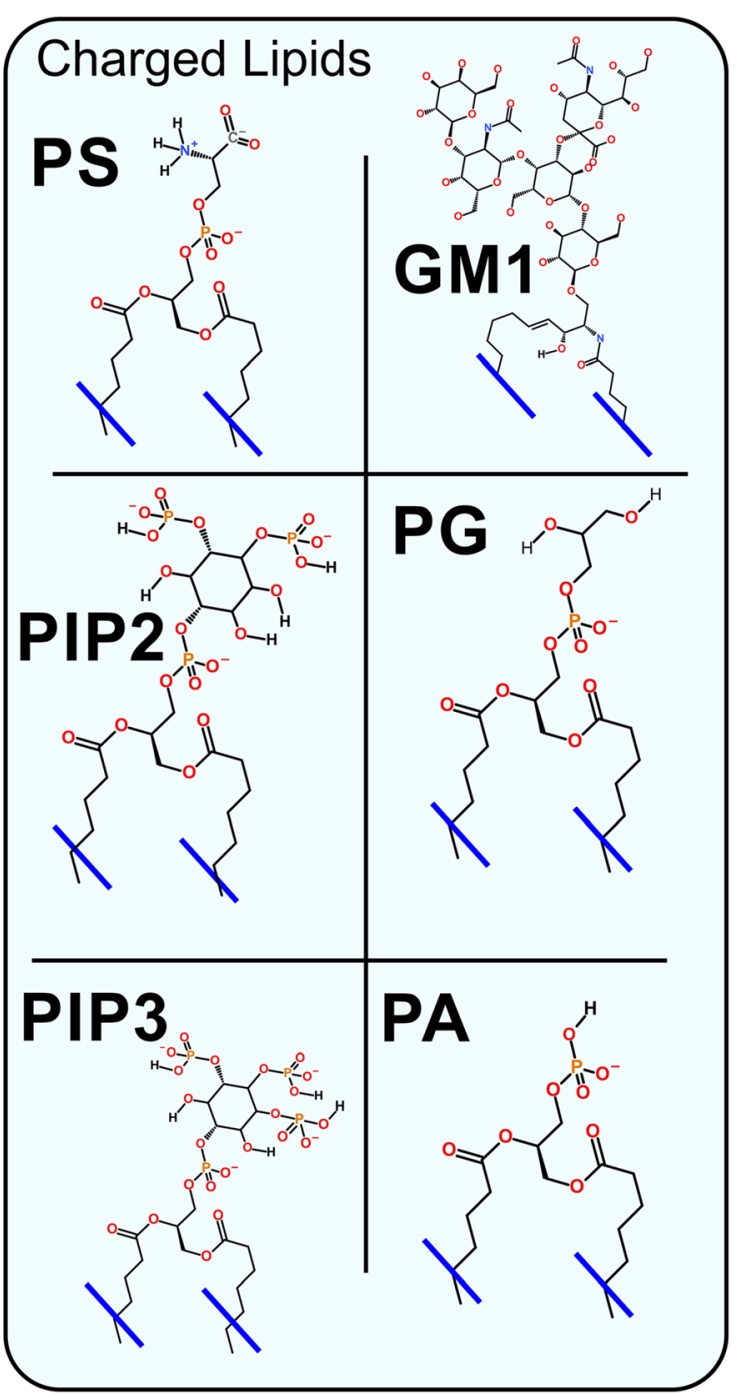

PS, phosphatidylserine; GM1, monosialotetrahexosylganglioside; PG, phosphatidylglycerol; PIP2, phosphatidylinositol bisphosphate; PIP3, phosphatidylinositol triphosphate; PA, phosphatidic acid

systems is fast $\left(2.2 \times 10^{-5} \mathrm{~cm}^{2} / \mathrm{s}\right)[112-114]$ and, moreover, the process is likely facilitated by aquaporins [73]. Thus, gaseous NTs should be able to diffuse and bind into their specific receptors regardless of their positioning in respect to the lipid bilayer.

\section{Neurotransmitter Transporters: Lipid-Assisted Neurotransmitter Entry?}

Synaptic receptors (Fig. 4) are not the only proteins in the synapse that bind and interact with the NTs. The neurotransmitter transporters with membrane-buried ligand-binding sites also bind NTs in order to transport them away from the synaptic cleft after their release and elicited function [115]. For example, with glutamate, the transport must be expedient due to its potentially toxic effects of the prolonged presence in the 
synapse [116]. The role of the transporters is complex because the NTs can also move in reverse through them in certain conditions [117] instead of relying on the presynaptic vesicle release (Fig. 5). Until very recently [118, 119], mechanistic insight into the neurotransmitter transporters has relied on Xray crystallographic structures of their bacterial counterparts such as leucine transporter [115].

The paradox is that even the most hydrophilic or lipophobic NTs (Fig. 2) that are not prone to adhere on the membrane (Fig. 3) must be transported actively away from the synapse through the transporters with the membrane-buried binding sites. The increased anionic or hydrogen-bonding capable lipid content within the membrane patches surrounding the transporter proteins, in theory, could assist the entry into the buried binding sites. While there is no evidence on the implied effect of direct NT-lipid interaction on the transport, the MLC has been shown to influence bacterial aspartate transporter conformation and function via specific pi-cation interactions [120]. Furthermore, the presence of charged amino acid residues at the water-membrane interface could assist at the early stage of NT entry into the transporters.

Acetylcholine, whose efficient entry into the muscarinic receptors (Fig. 4) seems to require highly anionic MLC based on the MD simulations [42], remains an odd example also when inspecting its removal from the synaptic cleft. Acetylcholine is catalyzed into choline and acetate by the acetylcholinesterase and, notably, the enzyme's ligand-binding site is extracellular and, thus, the positively charged NT removal is not directly dependent on its membrane adhesion.

\section{Presynaptic Vesicle: Three Fail-Safes for Assuring Efficient Neurotransmitter Release}

The pre- and postsynaptic membranes are not the only lipid bilayer surfaces (Fig. 4) that NTs interact with during the neurotransmission. Upon the arrival of the action potential, the aggregation of PIPs (Fig. 6) instigates the protein assembly leading to the release of the NTs from the presynaptic vesicles into the synaptic cleft [13]. For this release to function fast and efficiently, the NTs, no matter how lipophilic (Fig. 2), should not aggregate excessively on the inner leaflet of the presynaptic vesicle as this would hinder the signaling overall.

There are at least three fail-safe mechanisms for preventing the unwanted membrane aggregation onto the inner leaflet of the vesicle (Fig. 5) [58]. Firstly, the lumen of the vesicle is kept relatively acidic (pH 5.6) in comparison with the physiological $\mathrm{pH}$ (7.4). The low $\mathrm{pH}$ assures that the negatively ionizable parts of lipid headgroups and NTs are more likely to be fully protonated/neutral and, thus, remain not attracted to each other [121]. The generated proton gradient also assists in the transport of the NTs into the vesicles by vesicular neurotransmitter transporters [121]. Secondly, the MLC of the vesicle's inner leaflet is composed of mainly neutral lipid species such as PC and phosphatidylethanolamine (PE) (Fig. 6), whereas the highly anionic PIP lipid is present in the outer leaflet $[77,78]$. Thirdly, positive and divalent cations $\mathrm{Ca}^{2+}$ and $\mathrm{Zn}^{2+}$ are actively pumped inside the vesicle where they can adhere on the anionic headgroups of the membrane lipids and neutralize the water-membrane interface $[121,122]$.

The charged MLC is crucial for the membrane adherence of NTs from both ends of the hydrophilicity and hydrophobicity scale $[42,51-56,60-67]$. Charge neutrality of the headgroup region of the membrane assists the release of all non-peptidic NTs regardless of their propensity to partition on the membrane in general (Figs. 3 and 6). This is more urgent when dealing with very lipophilic NTs because they tend to aggregate onto the water-membrane interface regardless of the MLC [42, 53, 60, 61, 65, 66] and, for example, dopamine almost entirely aggregates on to the membrane in the MD simulations [42, 60] (Fig. 3). This membrane preference of dopamine is predicted to be prevented almost entirely by the neutral MLC, and high calcium levels present inside the presynaptic vesicles based on the simulations and free energy calculations [58]. Nevertheless, the mechanisms for detachment of lipophilic NTs and drugs from various membranes in the synapse remain mostly unknown and, thus, require more scrutiny in the future.

\section{Role of Membranes in Intracellular Neurotransmitter Metabolism}

What is also not well recognized in the current literature is that both the synthesis and degradation of amphipathic NTs happen within the context of membranes. While there might not exist direct evidence of membrane assistance in these intracellular metabolic processes, for example, in the case of dopamine, the essential proteins are membrane-bound or membrane-associated based on the latest research.

Dopamine, the first catechol NT at the biosynthetic pathway, is synthesized from the amino acid tyrosine in two steps: (1) the tyrosine hydroxylase converts it to L-dopa, and (2) the L-dopa decarboxylase converts it into dopamine. Although both enzymes were previously considered to be cytosolic, recent studies have indicated their association with membranes: the tyrosine hydroxylase binds to liposomes [123], and the L-dopa decarboxylase associates generally with the membranes in the cellular environment [124]. In the next step, dopamine is used as a substrate in the synthesis of two other catechol NTs: (1) norepinephrine and (2) epinephrine. The first step of the conversion is performed by the dopamine- $\beta$ hydroxylase enzyme that has both water-soluble and membrane-bound forms [125]. An alternative pathway of dopamine biosynthesis utilizes the cytochrome P450 enzyme 
[126], which is an established integral membrane protein. Degradation of dopamine after its reuptake is an essential process due to the toxicity of its oxidized form [127]. The initial steps of dopamine degradation are suggested to be performed by four different enzymes, including the membraneassociated monoamine oxidize [128] and uridine diphosphoglucuronosyltransferases [129], and, finally, catechol-omethyl transferase (COMT) [130] and sulfotransferase [131] that have both membrane-bound and water-soluble forms.

\section{The Effect of Membrane Sorting for Drugs and Beyond}

The studies reviewed in this perspective indicate that the NTmembrane interactions are likely to be tightly regulated and, therefore, a crucial part of the synaptic neurotransmission. This level of organization and coordination is needed because the NT diffusion across the synaptic cleft $(20-30 \mathrm{~nm})$ takes only a few microseconds [132]. Moreover, the membranebased sorting (Fig. 4) not only affects neurotransmission efficiency but likely extend to all phases of the NT life cycle, including their release from the synaptic vesicles, diffusion across the cleft, receptor entry or binding, removal from the synaptic cleft, as well as their production and eventual degradation.

The potential role of the membrane sorting (Fig. 5) should not be overlooked with any small molecules or ligands due to the ubiquitous presence of membranes in the synaptic cleft (Fig. 1) or, ultimately, inside or outside of any cell. If a drug is due to enter a cell membrane-buried or an extracellular ligand-binding site (Fig. 5), its binding rate should benefit

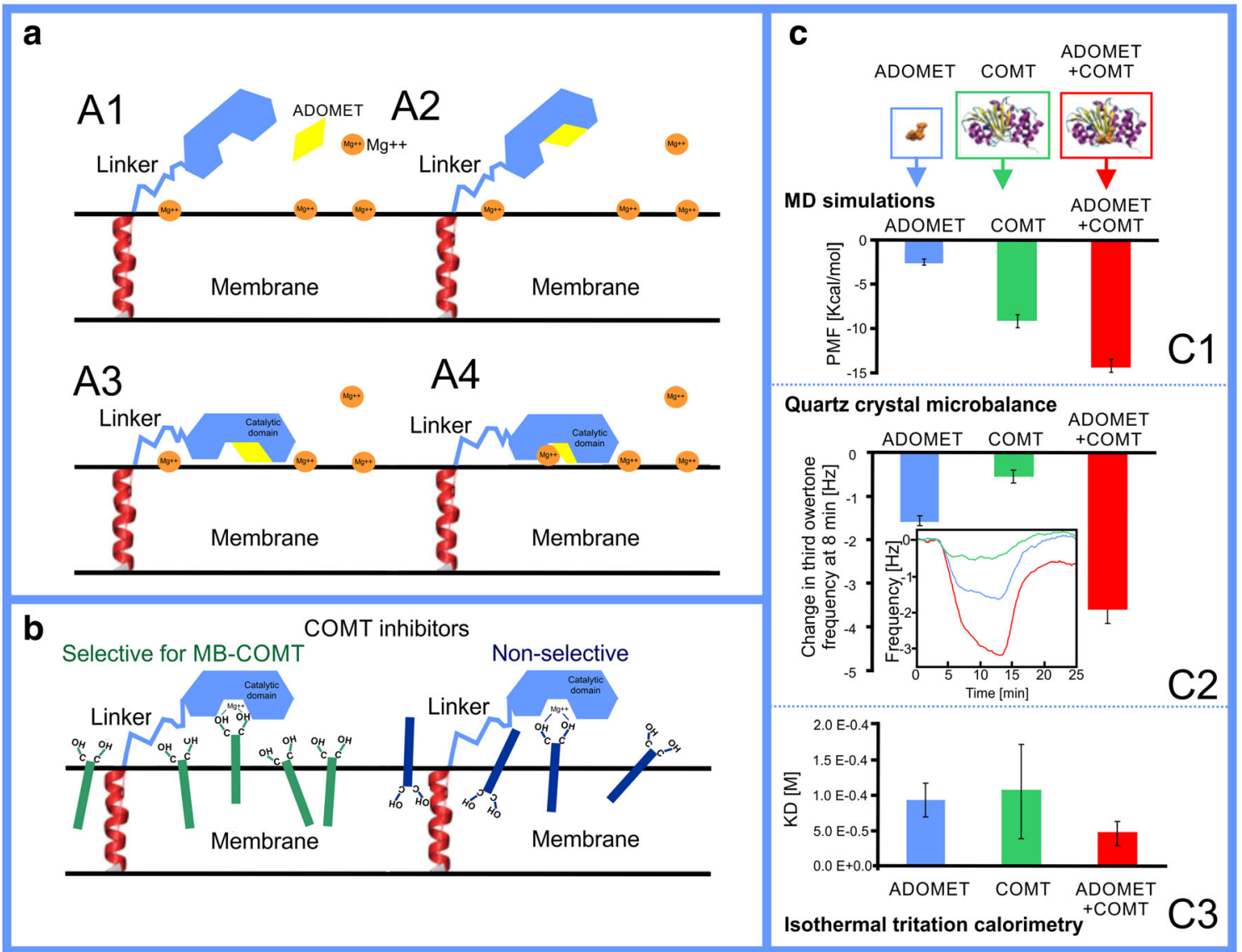

Fig. 7 The pivotal role of the membrane in membrane-bound catechol-omethyl transferase catalysis and selective inhibition. a Steps of catalytic mechanism of the membrane-bound catechol-o-methyl transferase (MBCOMT): (A1) the catalytic domain interacts weakly with membrane in the apo form; (A2) the cofactor S-adenosyl-L-methionine (ADOMET) binds to the catalytic site of MB-COMT; (A3) MB-COMT in complex with ADOMET opens the catalytic site towards the membrane, which, in turn, allows the protein to bind to the membrane surface; (A4), finally, the MB-COMT binds an $\mathrm{Mg}^{2+}$ ion that is already present at the membrane surface. $\mathbf{b}$ The behavior of MB-COMT selective vs. non-selective inhibitors in the membrane: selective inhibitors orient catechol group towards the water phase and, in contrast, non-selective inhibitors could be oriented less optimally in relation to the MB-COMT catalytic site. $\mathbf{c}$ The estimations of interactions of the ADOMET and catalytic domain of COMT in complex and separately with lipids indicate that the catalytic domain is preferably membrane-oriented: $(\mathrm{C} 1)$ the free energy changes when protein is pulled away from the lipid bilayer; (C2) quartz crystal microbalance $(\mathrm{QCM})$ frequency changes during interaction with the lipid bilayer; (C3) dissociation constant (inverse of affinity) from lipid bilayer (vesicle) determined by isothermal calorimetry. Reproduced with permission from ref. [146]. Copyright 2018 the Royal Society of Chemistry 
from the sorting (Fig. 1a) [40, 42]. This is analogous to matching the charge/shape properties between the receptors' ligand-binding sites with those of the ligands during docking [133-136], docking rescoring [137-139], or drug discovery [136, 140-142]. In fact, there is overwhelming evidence of the affinity of small molecules towards lipids [28], and the MLC is also known to affect drug membrane permeability [143]. The $\log P$ values, membrane permeation, and lipophilic efficiency are already routinely considered in the medicinal chemistry [144]. The difference between the drugs and NTs is that the synaptic MLCs are fine-tuned through evolution for the unobstructed dynamics of the latter group and not necessarily for the former [42]. However, if a drug binds into the same ligand-binding site as the endogenous ligand (not an allosteric modulator), it is likely to have a similar charge profile for interacting with the membrane. For example, the ligand-binding sites of ionotropic glutamate receptors are highly charged to match the opposite charge profile of its ligands, mainly glutamate [145] - a feature that also affects their dynamics with the membrane (Fig. 1a) [42].

The importance of membranes for drug development was clearly demonstrated in a recent study showing dependency between inhibitor membrane location and orientation in respect to the membrane surface (Fig. 7), and its selectivity towards the membrane-bound form of catechol-o-methyl transferase (MB-COMT) compared with its water-soluble form (S-COMT) [146]. The COMT inhibitors are used together with L-dopa in the treatment of Parkinson's disease to prevent dopamine deficit [147, 148]. L-Dopa is converted into dopamine inside the neurons, and the role of COMT inhibitors in the drug formulation is to prevent L-dopa degradation. Interestingly, in the brain tissues, the MB-COMT dominates, while in the remaining part of the body, the S-COMT is dominant. For this reason, the development of MB-COMTspecific drugs (Fig. 7b) is beneficial due to the likely reduction in the undesired side effects.

\section{Conclusions}

All four components, the neurotransmitter (NT), the membrane lipid composition (MLC), the shape/charge of the receptor's binding site, and its location in relation to the lipid bilayer, should match; otherwise, the efficiency of the neurotransmission is bound to suffer. If an NT is due to binding into an extracellular ligand-binding site, it does not adhere firmly on the membrane surface. In contrast, an NT that binds into a membrane-embedded ligand-binding site has a strong tendency to adhere to the membrane as well. This division of neurotransmission into the membrane-independent and membranedependent mechanisms is supported by molecular dynamics simulations, X-ray crystallography, $\log P$ values, and other sensitive biophysical experiments. Even prior to an NT release into the synaptic cleft, prohibitively strong membrane adherence of NTs is prevented by controlling the MLC of the inner leaflet, $\mathrm{pH}$, and ionic content of the presynaptic vesicles. In fact, an NT dynamics is likely to be affected by the membrane environment during their transport out of the cleft as well as their intracellular synthesis and degradation. Collectively, the data supports the view that individual synapses, which are specific for certain NTs, have carefully curated global and/or local MLCs to assure fast neurotransmission and avoid potential disease states caused by NT-membrane mismatches. In short, the membrane should not be seen as a passive barrier or a mere scaffold for proteins, but rather as an active participant or even a nexus that facilitates the fast-paced synaptic neurotransmission.

Acknowledgments The Finnish IT Center for Science (CSC) is acknowledged for generous computational resources.

Funding information Open access funding provided by University of Helsinki including Helsinki University Central Hospital. This work was supported by the Academy of Finland (Center of Excellence program; grant no. 307415) (T.R.). The Paulo Foundation and the Academy of Finland (grant no. 268130) are acknowledged for supporting P.A.P.

\section{Compliance with Ethical Standards}

This article does not contain any studies with human participants or animals performed by any of the authors.

Conflict of Interest The authors declare that they have no conflict of interest.

Open Access This article is distributed under the terms of the Creative Commons Attribution 4.0 International License (http:// creativecommons.org/licenses/by/4.0/), which permits unrestricted use, distribution, and reproduction in any medium, provided you give appropriate credit to the original author(s) and the source, provide a link to the Creative Commons license, and indicate if changes were made.

\section{References}

1. Zucker RS, Kullmann DM, Kaeser PS (2014) Release of Neurotransmitters. In: Byrne JH, Heidelberger R, Waxham MN (eds) From Molecules to Networks. Elsevier Inc., pp 443-488

2. Deutch AY, Roth RH (2014) Pharmacology and Biochemistry of Synaptic Transmission Classical Transmitters. In: Byrne JH, Heidelberger R, Waxham MN (eds) From Molecules to Networks. Elsevier Inc., pp 207-237

3. Chua JJE, Kindler S, Boyken J, Jahn R (2010) The architecture of an excitatory synapse. J Cell Sci 123:819-823. https://doi.org/10. $1242 /$ jcs. 052696

4. Dieterich DC, Kreutz MR (2016) Proteomics of the synapse - a quantitative approach to neuronal plasticity. Mol Cell Proteomics 15:368-381. https://doi.org/10.1074/mcp.R115.051482

5. Takahashi T (2015) Strength and precision of neurotransmission at mammalian presynaptic terminals. Proc Jpn Acad Ser B Phys Biol Sci 91:305-320. https://doi.org/10.2183/pjab.91.305

6. Koopmans F, Pandya NJ, Franke SK, Phillippens IHCMH (2018) Comparative hippocampal synaptic proteomes of rodents and 
primates: differences in neuroplasticity-related proteins. Front Mol Neurosci 11:1-14. https://doi.org/10.3389/fnmol.2018.00364

7. Hondiusa DC, van Nierop P, Li KW et al (2016) Profiling the human hippocampal proteome at all pathologic stages of Alzheimer' s disease. Alzheimers Dement 12:654-668. https:// doi.org/10.1016/j.jalz.2015.11.002

8. Yoshii A, Constantine-Paton M (2010) Postsynaptic BDNF-TrkB signaling in synapse maturation, plasticity, and disease. Dev Neurobiol 70:304-322. https://doi.org/10.1002/dneu.20765

9. Suzuki S, Numakawa T, Shimazu K, Koshimizu H, Hara T, Hatanaka H, Mei L, Lu B et al (2004) BDNF-induced recruitment of TrkB receptor into neuronal lipid rafts: roles in synaptic modulation. J Cell Biol 167:1205-1215. https://doi.org/10.1083/jcb. 200404106

10. Dietschy JM, Turley SD (2004) Cholesterol metabolism in the central nervous system during early development and in the mature animal. J Lipid Res 45:1375-1397. https://doi.org/10.1194/jlr. R400004-JLR200

11. Lieto A, Rantamäki T, Vesa L et al (2012) The responsiveness of trkb to bdnf and antidepressant drugs is differentially regulated during mouse development. PLoS One 7:e32869. https://doi. org/10.1371/journal.pone.0032869

12. Puchkov D, Haucke V (2013) Greasing the synaptic vesicle cycle by membrane lipids. Trends Cell Biol 23:493-503. https://doi.org/ 10.1016/j.tcb.2013.05.002

13. Lauwers E, Goodchild R, Verstreken P (2016) Membrane lipids in presynaptic function and disease. Neuron 90:11-25. https://doi. org/10.1016/j.neuron.2016.02.033

14. Yang Z, Gou L, Chen S, Li N, Zhang S, Zhang L (2017) Membrane fusion involved in neurotransmission: glimpse from electron microscope and molecular simulation. Front Mol Neurosci 10:168. https://doi.org/10.3389/fnmol.2017.00168

15. Bilkova E, Pleskot R, Rissanen S, Sun S, Czogalla A, Cwiklik L, Róg T, Vattulainen I et al (2017) Calcium directly regulates phosphatidylinositol 4,5-bisphosphate headgroup conformation and recognition. J Am Chem Soc 139:4019-4024. https://doi.org/10. 1021/jacs. 6 b 11760

16. Orłowski A, Kukkurainen S, Pöyry A, Rissanen S, Vattulainen I, Hytönen VP, Róg T (2015) PIP2 and talin join forces to activate integrin. J Phys Chem B 119:12381-12389. https://doi.org/10. 1021/acs.jpcb.5b06457

17. Kulig W, Korolainen H, Zatorska M et al (2019) Complex behavior of phosphatidylcholine - phosphatidic acid bilayers and monolayers: effect of acyl chain unsaturation. Langmuir 35:5944-5956. https://doi.org/10.1021/acs.langmuir.9b00381

18. Nguyen N, Shteyn V, Melia TJ (2017) Sensing membrane curvature in macroautophagy. J Mol Biol 429:457-472. https://doi.org/ 10.1016/j.jmb.2017.01.006

19. Jafurulla M, Chattopadhyay A (2013) Membrane lipids in the function of serotonin and adrenergic receptors. Curr Med Chem 20:47-55. https://doi.org/10.2174/0929867311302010006

20. Fatakia SN, Sarkar P, Chattopadhyay A (2019) A collage of cholesterol interaction motifs in the serotonin 1A receptor: an evolutionary implication for differential cholesterol interaction. Chem Phys Lipids 221:184-192. https://doi.org/10.1016/j.chemphyslip. 2019.02.010

21. Virginia M, Sofía A, Barrantes FJ (2016) The lipid habitats of neurotransmitter receptors in brain. Biochim Biophys Acta Biomembr 1858:2662-2670. https://doi.org/10.1016/j.bbamem. 2016.07.005

22. Kim HY, Huang BX, Spector AA (2014) Phosphatidylserine in the brain: metabolism and function. Prog Lipid Res 56:1-18. https:// doi.org/10.1016/j.plipres.2014.06.002

23. Luessen DJ, Chen R (2016) Psychostimulants, brain membrane lipids and dopamine transmission. Biomolecular Research \& Therapeutics 5:2. https://doi.org/10.4172/2167-7956.1000143
24. Manna M, Niemelä M, Tynkkynen J, Javanainen M, Kulig W, Müller DJ, Rog T, Vattulainen I (2016) Mechanism of allosteric regulation of $\beta_{2}$-adrenergic receptor by cholesterol. Elife 5: e18432. https://doi.org/10.7554/eLife.18432

25. Guixà-González R, Albasanz JL, Rodriguez-Espigares I, Pastor M, Sanz F, Martí-Solano M, Manna M, Martinez-Seara H, Hildebrand PW, Martín M, Selent J (2017) Membrane cholesterol access into a G-protein-coupled receptor. Nat Commun 8:14505. https://oi.org/10.1038/ncomms14505

26. Liu RZ, Mita R, Beaulieu M, Gao Z, Godbout R (2010) Fatty acid binding proteins in brain development and disease. Int J Dev Biol 54:1229-1239. https://doi.org/10.1387/ijdb.092976rl

27. Guixà-González R, Javanainen M, Gómez-Soler M, Cordobilla B, Domingo JC, Sanz F, Pastor M, Ciruela F et al (2016) Membrane omega-3 fatty acids modulate the oligomerisation kinetics of adenosine $\mathrm{A}_{2 \mathrm{~A}}$ and dopamine $\mathrm{D}_{2}$ receptors. Sci Rep 6:19839. https:// doi.org/10.1038/srep19839

28. Enkavi G, Javanainen M, Kulig W, Róg T, Vattulainen I (2019) Multiscale simulations of biological membranes: the challenge to understand biological phenomena in a living substance. Chem Rev 119:5607-5774. https://doi.org/10.1021/acs.chemrev. 8 b00538

29. Wacker D, Wang S, McCorvy JD et al (2017) Crystal structure of an LSD-bound human serotonin receptor. Cell 168:377-389. https://doi.org/10.1016/j.cell.2016.12.033

30. Hua T, Vemuri K, Nikas SP, Laprairie RB, Wu Y, Qu L, Pu M, Korde A et al (2017) Crystal structures of agonist-bound human cannabinoid receptor CB 1. Nature 547:468-471. https://doi.org/ 10.1038/nature23272

31. Huang W, Manglik A, Venkatakrishnan AJ, Laeremans T, Feinberg EN, Sanborn AL, Kato HE, Livingston KE et al (2015) Structural insights into $\mu$-opioid receptor activation. Nature 524:315-321. https://doi.org/10.1038/nature14886

32. Che T, Majumdar S, Zaidi SA et al (2018) Structure of the nanobody-stabilized active state of the kappa opioid receptor. Cell 172:55-67 https://doi.org/10.1016/j.cell.2017.12.011

33. Thal DM, Sun B, Feng D, Nawaratne V, Leach K, Felder CC, Bures MG, Evans DA et al (2016) Crystal structures of the M1 and M4 muscarinic acetylcholine receptors. Nature 531:335-340. https://doi.org/10.1038/nature17188

34. Cheng RKY, Segala E, Robertson N et al (2017) Structures of human $A_{1}$ and $A_{2 A}$ adenosine receptors with xanthines reveal determinants of selectivity. Structure 25:1275-1285. https://doi. org/10.1016/j.str.2017.06.012

35. Coleman JA, Gouaux E (2018) Structural basis for recognition of diverse antidepressants by the human serotonin transporter. Nat Struct Mol Biol 25:170-175. https://doi.org/10.1038/s41594018-0026-8

36. Penmatsa A, Wang KH, Gouaux E (2015) X-ray structures of Drosophila dopamine transporter in complex with nisoxetine and reboxetine. Nat Struct Mol Biol 22:506-508. https://doi.org/10. 1038/nsmb.3029

37. Hottman DA, Li L (2014) Protein prenylation and synaptic plasticity: implications for Alzheimer's disease. Mol Neurobiol 50: 177-185. https://doi.org/10.1007/s12035-013-8627-Z

38. Fukata Y, Fukata M (2010) Protein palmitoylation in neuronal development and synaptic plasticity. Nat Rev Neurosci 11:161175. https://doi.org/10.1038/nrn2788

39. Cramariuc O, Rogl T, Vattulainen I (2012) Drug-lipid membrane molecular simulations interaction mechanisms revealed through molecular simulations. Curr Phys Chem 2:379-400

40. Vauquelin G, Packeu A (2009) Ligands, their receptors and ... plasma membranes. Mol Cell Endocrinol 311:1-10. https://doi. org/10.1016/j.mce.2009.07.022

41. Mayne CG, Arcario MJ, Mahinthichaichan P, Baylon JL, Vermaas JV, Navidpour L, Wen PC, Thangapandian S et al (2016) The 
cellular membrane as a mediator for small molecule interaction with membrane proteins. Biochim Biophys Acta Biomembr 1858:2290-2304. https://doi.org/10.1016/j.bbamem.2016.04.016

42. Postila PA, Vattulainen I, Róg T (2016) Selective effect of cell membrane on synaptic neurotransmission. Sci Rep 6:19345. https://doi.org/10.1038/srep19345

43. Wilkosz N, Rissanen S, Cyza M, Szybka R, Nowakowska M, Bunker A, Róg T, Kepczynski M (2017) Effect of piroxicam on lipid membranes: drug encapsulation and gastric toxicity aspects. Eur J Pharm Sci 100:116-125. https://doi.org/10.1016/j.ejps. 2017.01.007

44. Dzieciuch-Rojek M, Poojari C, Bednar J, Bunker A, Kozik B, Nowakowska M, Vattulainen I, Wydro P et al (2017) Effects of membrane PEGylation on entry and location of antifungal drug itraconazole and their pharmacological implications. Mol Pharm 14:1057-1070. https://doi.org/10.1021/acs.molpharmaceut. $6 \mathrm{~b} 00969$

45. Poojari C, Wilkosz N, Lira RB, Dimova R, Jurkiewicz P, Petka R, Kepczynski M, Róg T (2019) Behavior of the DPH fluorescence probe in membranes perturbed by drugs. Chem Phys Lipids 223: 104784. https://doi.org/10.1016/j.chemphyslip.2019.104784

46. Lajunen T, Kontturi LS, Viitala L, Manna M, Cramariuc O, Róg T, Bunker A, Laaksonen T et al (2016) Indocyanine green-loaded liposomes for light-triggered drug release. Mol Pharm 13:20952107. https://doi.org/10.1021/acs.molpharmaceut.6b00207

47. Lajunen T, Nurmi R, Wilbie D, Ruoslahti T, Johansson NG, Korhonen O, Rog T, Bunker A et al (2018) The effect of light sensitizer localization on the stability of indocyanine green liposomes. J Control Release 284:213-223. https://doi.org/10.1016/j. jconrel.2018.06.029

48. Harayama T, Riezman H (2018) Understanding the diversity of membrane lipid composition. Nat Rev Mol Cell Biol 19:281-296. https://doi.org/10.1038/nrm.2017.138

49. Mason RP, Rhodes DG, Herbette LG et al (1991) Reevaluating equilibrium and kinetic binding parameters for lipophilic drugs based on a structural model for drug interaction with biological membranes. J Med Chem 34:869-877. https://doi.org/10.1021/ jm00107a001

50. Zou S, Kumar U (2018) Cannabinoid receptors and the endocannabinoid system: Signaling and function in the central nervous system. Int J Mol Sci 19. https://doi.org/10.3390/ ijms 19030833

51. Sahin I, Bilge D, Kazanci N, Severcan F (2013) Concentrationdependent effect of melatonin on DSPC membrane. J Mol Struct 1052:183-188. https://doi.org/10.1016/j.molstruc.2013.08.060

52. Saija A, Tomaino A, Trombetta D, Pellegrino ML, Tita B, Caruso S, Castelli F (2002) Interaction of melatonin with model membranes and possible implications in its photoprotective activity. Eur J Pharm Biopharm 53:209-215. https://doi.org/10.1016/ S0939-6411(01)00239-9

53. Dies H, Cheung B, Tang J, Rheinstädter MC (2015) The organization of melatonin in lipid membranes. Biochim Biophys Acta Biomembr 1848:1032-1040. https://doi.org/10.1016/j.bbamem. 2015.01.006

54. Peters GH, Wang C, Cruys-Bagger N, Velardez GF, Madsen JJ, Westh P (2013) Binding of serotonin to lipid membranes. J Am Chem Soc 135:2164-2171. https://doi.org/10.1021/ja306681d

55. Berry MD, Shitut MR, Almousa A, Alcorn J, Tomberli B (2013) Membrane permeability of trace amines: evidence for a regulated, activity-dependent, nonexocytotic, synaptic release. Synapse 67: 656-667. https://doi.org/10.1002/syn.21670

56. Wang C, Ye F, Valardez GF et al (2011) Affinity of four polar neurotransmitters for lipid bilayer membranes. J Phys Chem B 115:196-203. https://doi.org/10.1021/jp108368w

57. Juhola H, Postila PA, Rissanen S, Lolicato F, Vattulainen I, Róg T (2018) Negatively charged gangliosides promote membrane association of amphipathic neurotransmitters. Neuroscience 384: 214-223. https://doi.org/10.1016/j.neuroscience.2018.05.035

58. Mokkila S, Postila PA, Rissanen S, Juhola H, Vattulainen I, Róg T (2017) Calcium assists dopamine release by preventing aggregation on the inner leaflet of presynaptic vesicles. ACS Chem Neurosci 8:1242-1250. https://doi.org/10.1021/acschemneuro. $6 \mathrm{~b} 00395$

59. Pérez-Isidoro R, Ruiz-Suárez JC (2016) Calcium and protons affect the interaction of neurotransmitters and anesthetics with anionic lipid membranes. Biochim Biophys Acta Biomembr 1858: 2215-2222. https://doi.org/10.1016/j.bbamem.2016.06.017

60. Orłowski A, Grzybek M, Bunker A, Pasenkiewicz-Gierula M, Vattulainen I, Männistö PT, Róg T (2012) Strong preferences of dopamine and 1-dopa towards lipid head group: importance of lipid composition and implication for neurotransmitter metabolism. J Neurochem 122:681-690. https://doi.org/10.1111/j.14714159.2012.07813.x

61. Shen C, Xue M, Qiu H, Guo W (2017) Insertion of neurotransmitters into a lipid bilayer membrane and its implication on membrane stability: a molecular dynamics study. ChemPhysChem 18: 626-633. https://doi.org/10.1002/cphc.201601184

62. Jodko-Piorecka K, Litwinienko G (2013) First experimental evidence of dopamine interactions with negatively charged model biomembranes. ACS Chem Neurosci 4:1114-1122. https://doi. org $/ 10.1021 / \mathrm{cn} 4000633$

63. Matam Y, Ray BD, Petrache HI (2016) Direct affinity of dopamine to lipid membranes investigated by nuclear magnetic resonance spectroscopy. Neurosci Lett 618:104-109. https://doi.org/10. 1016/j.neulet.2016.02.052

64. Das S, Purkayastha P A Fluorescence lifetime imaging microscopy supported investigation on temperature-dependent penetration of dopamine in a 1,2-ditetradecanoyl-sn-glycero-3-phospho-(1'rac-glycerol) Lipid Bilayer. Langmuir 29:7281-7287. https://doi. org/10.1021/acs.langmuir.7b01173

65. Drolle E, Kučerka N, Hoopes MI, Choi Y, Katsaras J, Karttunen M, Leonenko Z (2013) Effect of melatonin and cholesterol on the structure of DOPC and DPPC membranes. Biochim Biophys Acta Biomembr 1828:2247-2254. https://doi.org/10.1016/j.bbamem. 2013.05.015

66. Choi Y, Attwood SJ, Hoopes MI, Drolle E, Karttunen M, Leonenko Z (2014) Melatonin directly interacts with cholesterol and alleviates cholesterol effects in dipalmitoylphosphatidylcholine monolayers. Soft Matter 10:206-213. https://doi.org/10.1039/c3sm52064a

67. De Lima VR, Caro MSB, Munford ML et al (2010) Influence of melatonin on the order of phosphatidylcholine-based membranes. J Pineal Res 49:169-175. https://doi.org/10.1111/j.1600-079X. 2010.00782.x

68. Yandrasitz JR, Cohn RM, Masley B, Delrowe D (1980) Evaluation of the binding of serotonin by isolated CNS acidic lipids. Neurochem Res 5:465-477. https://doi.org/10.1007/ BF00964984

69. Mustafa AK, Gadalla MM, Snyder SH (2009) Signaling by gasotransmitters. Sci Signal 2:re2. https://doi.org/10.1126/ scisignal.268re2.Signaling

70. Cirino CG, Federico N, Montesano D et al (2017) Nitric oxide and hydrogen sulfide : the gasotransmitter paradigm of the vascular system. Br J Pharmacol 174:4021-4031. https://doi.org/10.1111/ bph.13815

71. Botti H, Batthyany C, Rubbo H et al (2005) Direct measurement of nitric oxide and oxygen partitioning into liposomes and low density lipoprotein. J Biol Chem 280:8850-8854. https://doi.org/ 10.1074/jbc.M413699200

72. Cuevasanta E, Denicola A, Alvarez B (2012) Solubility and permeation of hydrogen sulfide in lipid membranes. PLoS One 7: e34562. https://doi.org/10.1371/journal.pone.0034562 
73. Wang Y, Tajkhorshid E (2010) Nitric oxide conduction by the brain aquaporin AQP4 Yi. Proteins Struct Funct Genet 78:661670. https://doi.org/10.1002/prot.22595.Nitric

74. Riahi S, Rowley CN (2014) Why can hydrogen sulfide permeate cell membranes? J Am Chem Soc 136:15111-15113. https://doi. org $/ 10.1021 / \mathrm{ja} 508063 \mathrm{~s}$

75. Jedlovszky P, Mezei M (2000) Calculation of the free energy profile of $\mathrm{H}_{2} \mathrm{O}, \mathrm{O}_{2}, \mathrm{CO}, \mathrm{CO}_{2}, \mathrm{NO}$, and $\mathrm{CHCl}_{3}$ in a lipid bilayer with a cavity insertion variant of the Widom method. J Am Chem Soc 122:5125-5131. https://doi.org/10.1021/ja000156z

76. Stimson LM, Vattulainen I, Rog T, Karttunen M (2005) Exploring the effect of xenon on biomembranes. Cell Mol Biol Lett 10:563569

77. Takamori S, Holt M, Stenius K, Lemke EA, Grønborg M, Riedel D, Urlaub H, Schenck S et al (2006) Molecular anatomy of a trafficking organelle. Cell 127:831-846. https://doi.org/10.1016/ j.cell.2006.10.030

78. Michaelson DM, Barkai G, Barenholz Y (1983) Asymmetry of lipid organization in cholinergic synaptic vesicle membranes. Biochem J 211:155-162. https://doi.org/10.1042/bj2110155

79. Saxton MJ (1989) Lateral diffusion in an archipelago. Distance dependence of the diffusion coefficient. Biophys J 56:615-622. https://doi.org/10.1016/S0006-3495(89)82708-0

80. Kruse AC, Kobilka BK, Gautam D, Sexton PM, Christopoulos A, Wess J (2014) Muscarinic acetylcholine receptors: Novel opportunities for drug development. Nat Rev Drug Discov 13:549-560. https://doi.org/10.1038/nrd4295

81. Sine SM (2012) End-plate acetylcholine receptor: structure, mechanism, pharmacology, and disease. Physiol Rev 92:1189-1234. https://doi.org/10.1152/physrev.00015.2011

82. Llorente A, Skotland T, Sylvänne T, Kauhanen D, Róg T, Orłowski A, Vattulainen I, Ekroos K et al (2013) Molecular lipidomics of exosomes released by PC-3 prostate cancer cells. Biochim Biophys Acta - Mol Cell Biol Lipids 1831:1302-1309. https://doi.org/10.1016/j.bbalip.2013.04.011

83. Pietiläinen KH, Róg T, Seppänen-Laakso T, Virtue S, Gopalacharyulu P, Tang J, Rodriguez-Cuenca S, Maciejewski A et al (2011) Association of lipidome remodeling in the adipocyte membrane with acquired obesity in humans. PLoS Biol 9: e1000623. https://doi.org/10.1371/journal.pbio.1000623

84. Astarita G, Piomelli D (2011) Towards a whole-body systems [multi-organ] lipidomics in Alzheimer's disease. Prostaglandins Leukot Essent Fat Acids 85:197-203. https://doi.org/10.1016/j. plefa.2011.04.021

85. Müller CP, Reichel M, Mühle C, Rhein C, Gulbins E, Kornhuber J (2015) Brain membrane lipids in major depression and anxiety disorders. Biochim Biophys Acta-Molecular Cell Biol Lipids 1851:1052-1065. https://doi.org/10.1016/j.bbalip.2014.12.014

86. Yang L, Li M, Shan Y, Shen S, Bai Y, Liu H (2016) Recent advances in lipidomics for disease research. J Sep Sci 39:38-50. https://doi.org/10.1002/jssc.201500899

87. Oliveira TG, Chan RB, Bravo FV, Miranda A, Silva RR, Zhou B, Marques F, Pinto Vet al (2016) The impact of chronic stress on the rat brain lipidome. Mol Psychiatry 21:80-88. https://doi.org/10. 1038/mp.2015.14

88. Narayan S, Thomas EA (2011) Sphingolipid abnormalities in psychiatric disorders: a missing link in pathology? Front Biosci 16: $1797-1810$

89. Tessier C, Sweers K, Frajerman A, Bergaoui H, Ferreri F, Delva C, Lapidus N, Lamaziere A et al (2016) Membrane lipidomics in schizophrenia patients: a correlational study with clinical and cognitive manifestations. Transl Psychiatry 6:e906. https://doi.org/10. 1038/tp.2016.142

90. Cermenati G, Mitro N, Audano M, Melcangi RC, Crestani M, de Fabiani E, Caruso D (2015) Lipids in the nervous system: from biochemistry and molecular biology to patho-physiology.
Biochim Biophys Acta - Mol Cell Biol Lipids 1851:51-60. https://doi.org/10.1016/j.bbalip.2014.08.011

91. Dawson G (2015) Measuring brain lipids HHS public access. Biochim Biophys Acta 1851:1026-1039. https://doi.org/10. 1016/j.bbalip.2015.02.007

92. Piomelli D, Astarita G, Rapaka R (2007) A neuroscientist's guide to lipidomics. Nat Rev Neurosci 8:743-754. https://doi.org/10. 1038/nrn2233

93. Bozek K, Wei Y, Yan Z, Liu X, Xiong J, Sugimoto M, Tomita M, Pääbo S et al (2015) Organization and evolution of brain lipidome revealed by large-scale analysis of human, chimpanzee, macaque, and mouse tissues. Neuron 85:695-702. https://doi.org/10.1016/j. neuron.2015.01.003

94. Van Meer G, Voelker DR, Feigenson GW (2008) Membrane lipids: where they are and how they behave. Nat Rev Mol Cell Biol 9:112-124. https://doi.org/10.1038/nrm2330

95. Lingwood CA (2011) Glycosphingolipid functions. Cold Spring Harb Perspect Biol 3:1-26. https://doi.org/10.1101/cshperspect. a004788

96. Degroote S, Wolthoorn J, Van Meer G (2004) The cell biology of glycosphingolipids. Semin Cell Dev Biol 15:375-387. https://doi. org/10.1016/j.semcdb.2004.03.007

97. Stoffel W, Bosio A (1997) Myelin glycolipids and their functions. Curr Opin Neurobiol 7:654-661. https://doi.org/10.1016/S09594388(97)80085-2

98. Eckhardt M (2008) The role and metabolism of sulfatide in the nervous system. Mol Neurobiol 37:93-103. https://doi.org/10. 1007/s12035-008-8022-3

99. Takahashi T, Suzuki T (2012) Role of sulfatide in normal and pathological cells and tissues. J Lipid Res 53:1437-1450. https:/ doi.org/10.1194/jlr.R026682

100. Cotman C, Blank ML, Moehl A, Snyder F (1969) Lipid composition of synaptic plasma membranes isolated from rat brain by zonal centrifugation. Biochemistry 8:4606-4612. https://doi.org/ 10.1021/bi00839a056

101. Lewis KT, Maddipati KR, Naik AR, Jena BP (2017) Unique lipid chemistry of synaptic vesicle and synaptosome membrane revealed using mass spectrometry. ACS Chem Neurosci 8:11631169. https://doi.org/10.1021/acschemneuro.7b00030

102. Tulodziecka K, Diaz-Rohrer BB, Farley MM, Chan RB, di Paolo G, Levental KR, Waxham MN, Levental I (2016) Remodeling of the postsynaptic plasma membrane during neural development. Mol Biol Cell 27:3480-3489. https://doi.org/10.1091/mbc.E1606-0420

103. Camargo N, Smit AB, Verheijen MHG (2009) SREBPs : SREBP function in glia - neuron interactions. FEBS J 276:628-636. https://doi.org/10.1111/j.1742-4658.2008.06808.x

104. Ferris HA, Perry RJ, Moreira GV, Shulman GI, Horton JD, Kahn CR (2017) Loss of astrocyte cholesterol synthesis disrupts neuronal function and alters whole-body metabolism. Proc Natl Acad Sci U S A 114:1189-1194. https://doi.org/10.1073/pnas. 1620506114

105. Mainali L, Feix JB, Hyde JS, Subczynski WK (2011) Membrane fluidity profiles as deduced by saturation-recovery EPR measurements of spin-lattice relaxation times of spin labels. J Magn Reson 212:418-425. https://doi.org/10.1016/j.jmr.2011.07.022

106. Subczynski WK, Wisniewska A, Subczynski WK et al (1994) Hydrophobic barriers of lipid bilayer membranes formed by reduction of water penetration by alkyl chain unsaturation and cholesterol. Biochemistry 33:7670-7681. https://doi.org/10.1021/ bi00190a022

107. Subczynski WK, Hyde JS, Ak K (1989) Oxygen permeability of phosphatidylcholine-cholesterol membranes. Proc Natl Acad Sci U S A 86:4474-4478. https://doi.org/10.1073/pnas.86.12.4474

108. Miersch S, Espey MG, Chaube R, Akarca A, Tweten R, Ananvoranich S, Mutus B (2008) Plasma membrane cholesterol 
content affects nitric oxide diffusion dynamics and signaling. J Biol Chem 283:18513-18521. https://doi.org/10.1074/jbc. M800440200

109. Zocher F, Van Der Spoel D, Pohl P, Hub JS (2013) Local partition coefficients govern solute permeability of cholesterol- containing membranes. Biophys J 105:2760-2770. https://doi.org/10.1016/j. bpj.2013.11.003

110. Subczynski WK, Lomnicka M, Hyde SJ (1996) Permeability of nitric oxide through lipid bilayer membranes. Free Radic Biol Med 24:343-349

111. Jedlovszky P, Mezei M (2003) Effect of cholesterol on the properties of phospholipid membranes. 2. Free energy profile of small molecules. J Phys Chem B 107:5322-5332. https://doi.org/10. 1021/jp021951x

112. Santos RM, Lourenço CF, Gerhardt GA, Cadenas E, Laranjinha J, Barbosa RM (2011) Neurochemistry international evidence for a pathway that facilitates nitric oxide diffusion in the brain. Neurochem Int 59:90-96. https://doi.org/10.1016/j.neuint.2011. 05.016

113. Möller MN, Denicola A (2018) Diffusion of nitric oxide and oxygen in lipoproteins and membranes studied by pyrene fluorescence quenching. Free Radic Biol Med 128:137-143. https://doi. org/10.1016/j.freeradbiomed.2018.04.553

114. Borland C, Moggridge G, Patel R, Patel S, Zhu Q, Vuylsteke A (2018) Permeability and diffusivity of nitric oxide in human plasma and red cells. Nitric Oxide 78:51-59. https://doi.org/10.1016/j. niox.2018.05.006

115. Focke PJ, Wang X, Larsson HP (2013) Neurotransmitter transporters: structure meets function. Structure 21:694-705. https:// doi.org/10.1016/j.str.2013.03.002

116. Lau A, Tymianski M (2010) Glutamate receptors, neurotoxicity and neurodegeneration. Pflugers Arch Eur J Physiol 460:525-542. https://doi.org/10.1007/s00424-010-0809-1

117. Sitte HH, Freissmuth M (2010) The reverse operation of $\mathrm{Na}+\mathrm{Cl}-$ coupled neurotransmitter transporters - why amphetamines take two to tango. J Neurochem 112:340-355. https://doi.org/10. 1111/j.1471-4159.2009.06474.x

118. Penmatsa A, Wang KH, Gouaux E (2013) X-ray structure of dopamine transporter elucidates antidepressant mechanism. Nature 503:85-90. https://doi.org/10.1038/nature12533

119. Coleman JA, Green EM, Gouaux E (2016) X-ray structures and mechanism of the human serotonin transporter. Nature 532:334 339. https://doi.org/10.1038/nature17629

120. McIlwain BC, Vandenberg RJ, Ryan RM (2015) Transport rates of a glutamate transporter homologue are influenced by the lipid bilayer. J Biol Chem 290:9780-9788. https://doi.org/10.1074/ jbc.M114.630590

121. Burré J, Volknandt W (2007) The synaptic vesicle proteome. J Neurochem 101:1448-1462. https://doi.org/10.1111/j.14714159.2007.04453.x

122. Betz WJ, Angleson JK (1998) The synaptic vesicle cycle. Annu Rev Physiol 60:347-363. https://doi.org/10.1146/annurev.physiol. 60.1.347

123. Baumann A, Jorge-Finnigan A, Jung-Kc K et al (2016) Tyrosine hydroxylase binding to phospholipid membranes prompts its amyloid aggregation and compromises bilayer integrity. Sci Rep 6: 39488. https://doi.org/10.1038/srep39488

124. Poulikakos P, Vassilacopoulou D, Fragoulis EG (2001) L-DOPA decarboxylase association with membranes in mouse brain. Neurochem Res 26:479-485. https://doi.org/10.1023/A: 1010952610387

125. Lewis EJ, Asnani LP (1992) Soluble and membrane-bound forms of dopamine beta-hydroxylase are encoded by the same mRNA. J Biol Chem 267:494-500
126. Meiser J, Weindl D, Hiller K (2013) Complexity of dopamine metabolism. Cell Commun Signal 11:1-18. https://doi.org/10. 1186/1478-811X-11-34

127. Riessland M, Kolisnyk B, Greengard P (2017) Reactive dopamine leads to triple trouble in nigral neurons. Biochemistry 56:6409 6410. https://doi.org/10.1021/acs.biochem.7b01057

128. Youdim MBH, Edmondson D, Tipton KF (2006) The therapeutic potential of monoamine oxidase inhibitors. Nat Rev Neurosci 7: 295-309. https://doi.org/10.1038/nrn1883

129 . N a gar S, Remmel RP (2 006 ) U ridine diphosphoglucuronosyltransferase pharmacogenetics and cancer. Oncogene 25:1659-1672. https://doi.org/10.1038/sj.onc.1209375

130. Craddock N, Owen MJ, O’Donovan MC (2006) The catechol-Omethyl transferase (COMT) gene as a candidate for psychiatric phenotypes: evidence and lessons. Mol Psychiatry 11:446-458. https://doi.org/10.1038/sj.mp.4001808

131. Gamage N, Barnett A, Hempel N, Duggleby RG, Windmill KF, Martin JL, McManus ME (2006) Human sulfotransferases and their role in chemical metabolism. Toxicol Sci 90:5-22. https:// doi.org/10.1093/toxsci/kfj061

132. Sabatini BL, Regehr WG (2002) Timing of synaptic transmission. Annu Rev Physiol 61:521-542. https://doi.org/10.1146/annurev. physiol.61.1.521

133. Virtanen SI, Pentikäinen OT (2010) Efficient virtual screening using multiple protein conformations described as negative images of the ligand-binding site. J Chem Inf Model 50:10051011. https://doi.org/10.1021/ci100121c

134. Niinivehmas SP, Virtanen SI, Lehtonen JV, Postila PA, Pentikäinen OT (2011) Comparison of virtual high-throughput screening methods for the identification of phosphodiesterase-5 inhibitors. J Chem Inf Model 51:1353-1363. https://doi.org/10. 1021/ci1004527

135. Niinivehmas SP, Salokas K, Lätti S, Raunio H, Pentikäinen OT (2015) Ultrafast protein structure-based virtual screening with panther. J Comput Aided Mol Des 29:989-1006. https://doi.org/ 10.1007/s10822-015-9870-3

136. Rauhamäki S, Postila PA, Niinivehmas S, Kortet S, Schildt E, Pasanen M, Manivannan E, Ahinko M et al (2018) Structureactivity relationship analysis of 3-phenylcoumarin-based monoamine oxidase B inhibitors. Front Chem 6:1-18. https://doi.org/ 10.3389/fchem.2018.00041

137. Kurkinen ST, Niinivehmas S, Ahinko M, Lätti S, Pentikäinen OT, Postila PA (2018) Improving docking performance using negative image-based rescoring. Front Pharmacol 9:260. https://doi.org/10. 3389/fphar.2018.00260

138. Jokinen EM, Postila PA, Ahinko M et al (2019) Fragment- and negative image-based screening of phosphodiesterase 10A inhibitors. Chem Biol Drug Des:1-14. https://doi.org/10.1111/cbdd. 13584

139. Kurkinen ST, Lätti S, Pentikäinen OT, Postila PA (2019) Getting docking into shape using negative image-based rescoring. J Chem Inf Model 59:3584-3599. https://doi.org/10.1021/acs.jcim. 9b00383

140. Nicholls A, McGaughey GB, Sheridan RP et al (2010) Molecular shape and medicinal chemistry: a perspective. J Med Chem 53 : 3862-3886. https://doi.org/10.1021/jm900818s

141. Niinivehmas SP, Manivannan E, Rauhamäki S, Huuskonen J, Pentikäinen OT (2016) Identification of estrogen receptor a ligands with virtual screening techniques. J Mol Graph Model 64: 30-39. https://doi.org/10.1016/j.jmgm.2015.12.006

142. Niinivehmas S, Postila PA, Rauhamäki S, Manivannan E, Kortet S, Ahinko M, Huuskonen P, Nyberg N et al (2018) Blocking oestradiol synthesis pathways with potent and selective coumarin derivatives. J Enzyme Inhib Med Chem 33:743-754. https://doi. org/10.1080/14756366.2018.1452919 
143. Tse CH, Comer J, Wang Y, Chipot C (2018) Link between membrane composition and permeability to drugs. J Chem Theory Comput 14:2895-2909. https://doi.org/10.1021/acs.jctc.8b00272

144. Freeman-Cook KD, Hoffman RL, Johnson TW (2013) Lipophilic efficiency: the most important efficiency metric in medicinal chemistry. Future Med Chem 5:113-115. https://doi.org/10. 4155/fmc. 12.208

145. Martins ACV, De-Lima-Neto P, Caetano EWS, Freire VN (2017) An improved quantum biochemistry description of the glutamateGluA2 receptor binding within an inhomogeneous dielectric function framework. New J Chem 41:6167-6179. https://doi.org/10. 1039/c6nj03939a

146. Magarkar A, Parkkila P, Viitala T, Lajunen T, Mobarak E, Licari G, Cramariuc O, Vauthey E et al (2018) Membrane bound COMT isoform is an interfacial enzyme: general mechanism and new drug design paradigm. Chem Commun 54:3440-3443. https:// doi.org/10.1039/C8CC00221E

147. Lewitt PA (2015) Levodopa therapy for Parkinson's disease: pharmacokinetics and pharmacodynamics. Mov Disord 30:64-72. https://doi.org/10.1002/mds.26082

148. Detrait ER, Carr GV, Weinberger DR, Lamberty Y (2016) Brain catechol-O-methyltransferase (COMT) inhibition by tolcapone counteracts recognition memory deficits in normal and chronic phencyclidine-treated rats and in COMT-Val transgenic mice. Behav Pharmacol 27:415-421. https://doi.org/10.1097/FBP. 0000000000000208

Publisher's Note Springer Nature remains neutral with regard to jurisdictional claims in published maps and institutional affiliations. 